\title{
BIOQ-BYWORD
}

\section{A Research on CALL-Based POA in English Writing Teaching}

\author{
Peipei Zhou* \\ Anqing Normal University School of Foreign Languages, Anqing 246133, China \\ *Corresponding author: Peipei Zhou, 1580870352@qq.com
}

\begin{abstract}
The combination of production-oriented approach (POA) and modern computer technology makes English learning and teaching more convenient and efficient. This research combines the computer-assisted language learning (CALL) mode with POA to form the online and offline hybrid teaching mode, aiming to provide a reference for English teachers.
\end{abstract}

Keywords: CALL-based POA; English writing teaching; Teaching design

Publication date: December 2021; Online publication: December 27, 2021

\section{Introduction}

\subsection{Research background}

As an international language, the importance of English cannot be undermined. Studies have shown that the level of English writing has a direct impact on the level of comprehensive language use among learners. In the future, the key research directions will be on how to reform English writing teaching and improve students' English writing level.

Production-oriented approach (POA) is a new research theory in foreign language teaching, which has attracted the interest of many researchers. However, the application of advanced POA theory to traditional classrooms has certain shortcomings. Therefore, this study will provide some interesting approaches to solve this problem. In order to overcome the obstacles where traditional classroom language materials are not rich enough and the communicative environment is not real enough, improving the richness of language materials and the authenticity of communicative environment are becoming more and more important.

In addition, Wen Qiufang, the founder of POA theory, called on researchers to be innovative and brave enough to combine advanced teaching theories with advanced teaching modes to explore more efficient teaching modes and methods, in order to improve teaching effects ${ }^{[1]}$.

\subsection{Overview of POA and CALL-based POA}

\subsubsection{Definition of POA}

The Chinese Foreign Language and Education Research Team, led by Wen Qiufang, has developed a theoretical system of POA after more than ten years of polishing and interaction between theory and practice ${ }^{[2]}$. The system consists of three parts: teaching principles, teaching hypotheses, and teaching procedures. The teaching principles include "learning-centered principle," "learning-using integration principle," "cultural exchange principle," and "key competence principle." The teaching hypotheses include "output-driven," "input-enabling," "selective learning," and "assessment to learning." Teaching procedures comprise of several cycles of motivating, enabling, and assessment. In the whole process, teachers should play a leading role and fully mobilize students' subjective initiative. 


\subsubsection{Definition of CALL}

Computer-assisted language learning (CALL) is becoming increasingly prominent in education. As a result, it is changing the face of teaching and learning ${ }^{[3]}$. While the driving force behind such innovations is multifaceted, the desire to raise the levels of teaching efficiency and quality has generally been regarded as a major contributing factor.

CALL is a relatively new term, having come into favor in the early 1980 s, replacing the older term CALI (computer-assisted language instruction). The term CALI fell out of favor because it became associated with programmed learning; that is, a teacher-centered approach rather than a learner-centered approach which drew heavily on behaviorism. Throughout the 1980s, CALL widened its scope, embracing the communicative approach and a range of new technologies. CALL now includes highly interactive and communicative support for listening, speaking, reading, and writing, including the extensive use of multimedia CD-ROMs and the internet.

An alternative term to CALL was introduced in the late 1980s - technology-enhanced language learning (TELL). The term provides a more accurate description of the activities which fall broadly within the range of CALL.

Given the breadth of what may go on in computer-assisted language learning (CALL), a definition of CALL that accommodates its changing nature is any process in which a learner uses a computer, and as a result, improves his or her language. Although this definition might be unworkably large, at least it encompasses a broad spectrum of current practice in the teaching and learning of language via computer.

According to Michael Levy, computer-assisted language learning can be defined as "the search for and the study of applications of computers in language teaching and learning."

Computer-assisted language learning should include the following aspects: (1) to help students learn English by means of computer; (2) to learn courses relevant to foreign languages by means of computer; (3) to learn the software required by foreign language majors; (4) to organize tests, calculate results, analyze questions, evaluate students' level, and set up test base by means of computer; (5) to carry out researches on applied linguistics by means of computer; (6) to organize multimedia instruction centered on computer; (7) to organize the whole system of foreign language teaching so as to make it scientific.

As can be seen from the above definitions and understanding, CALL includes both teaching and learning activities.

In this study, CALL is defined as the teaching and researching activities that take advantage of computer technology, including the single computer, local area network, and the internet.

\subsubsection{Definition of CALL-based POA}

CALL-based POA combines traditional offline teaching with computer-assisted online learning using computer tools familiar to teachers and students. CALL-based POA teaching is mainly divided into three teaching steps: online drive, offline facilitation, as well as online and offline assessment.

\section{Related studies on CALL-based English writing teaching abroad and at home}

\subsection{Related studies on CALL-based English writing teaching abroad}

The integration of computer network and English teaching has started in foreign countries long ago. In the 1970s, computers were first introduced into the English classroom and were mainly used for the teaching of language knowledge and to complete classroom exercises. In the 1980s, with the emergence of cognitive learning theory, language learning paid more attention to discourse, highlighting the cultivation of students' cognitive ability; at that time, the use of computers also changed from assisting teachers in teaching to assisting students in learning. In the 1990s, with the development of constructivism learning theory, 
computer-assisted language learning (CALL) began to rise. Teachers would use computer tools to create real situations for students, stimulate students' interest in learning, as well as cultivate their communicative and independent learning skills.

Since the 21st century, the development of computer network technology is advancing by leaps and bounds. Many scholars have applied it to the field of teaching; in addition, the breadth and depth of relevant research have increased. Computers are not only tools to assist language teaching, but teachers are more concerned about how the teacher-student relationship, teaching content, and teaching effect change in such an environment.

Many foreign researchers have proven that CALL-based English writing teaching has a good application effect. It has been suggested that computer networks can help learners build real context and maximize their subjective initiative. Dan Lu believes that the emergence of computer networks plays a significant role in improving learners' autonomous learning ability ${ }^{[4]}$. American researchers, Pei-Lin Liu and Chiu-Jung Chen found that compared with traditional teaching methods, CALL can increase students' interest in learning and improve the teaching effect ${ }^{[5,6]}$. In addition, several researchers have put forward their own suggestions for CALL-based English writing teaching. The future focus of the integration of computer network and English writing teaching should be to make use of the ubiquitous characteristics of computer network to integrate informal learning with formal learning as well as break the limitations of former learning time and space. Teaching examples have been used to show how teachers guide students to become masters of learning under the environment of computer network.

To sum up, foreign research on computer network in English writing teaching has achieved some results. Research abroad alone has gained experience with the tools of computer network for the auxiliary teaching of language knowledge, paying attention to cultivate students' communicative competence, and then building a network teaching platform to cultivate students' autonomous learning ability; however, it can be seen that there are some deficiencies in the existing literatures abroad on English writing teaching based on CALL.

The research subjects are mainly limited to high-level learners. Future research should incline toward basic education as well as improve the network literacy of teachers and students, so as to facilitate the development of research.

\subsection{Related studies on CALL-based English writing teaching at home}

Domestic research on English writing teaching mainly focuses on the teaching model and technology application. The research on teaching model mainly covers three aspects. The first is to build a new teaching model by integrating foreign language teaching theories with computer network. A multi-teaching assessment mechanism based on computer network and supported by project-based learning promotion assessment has been introduced, thus providing some useful thoughts for assessment in English writing teaching. The second is to innovate the teaching model with constantly updated educational technology ideas. An interactive teaching model for college English writing has also been introduced. It is assisted by an automatic essay correcting system and the effectiveness of the model has been verified. Third, the blended teaching model is gradually being favored. It has been found that blended teaching has a huge impact on learning motivation, and the main influencing factors include rich and diverse teaching resources, network teaching platform, modern educational means, metacognitive strategies, etc.

To sum up, although the new English writing teaching mode based on computer network has different perspectives, it is mostly based on relevant theories in combination with teaching practices to verify the effectiveness of the constructed teaching model.

From the aspect of network technology application, it mainly focuses on the role of QQ, e-mail, blog, wiki, and other existing network platforms in English writing teaching. The influence of blog-based English 
writing teaching method on the writing level of English majors has been studied. The results showed that the students fancied this teaching method and their writing level improved. A new college English writing teaching model has been constructed based on the collaboration theory and wiki as the teaching platform. The teaching flow chart and each teaching link have been designed and introduced in detail.

The purpose of this study is to introduce CALL-based POA into high school English writing teaching and help teachers to realize the importance of CALL-based POA. At the same time, this study aims at helping the students to enjoy writing.

\section{Teaching design of CALL-based POA}

The network tools include micro video, PowerPoint (PPT), correcting network application, and Chaoxing App.

\subsection{Motivating stage}

In the motivating stage, the main task is to assist students to realize their shortcomings through output, so as to mobilize their enthusiasm and stimulate their desire for learning.

Teachers are required to design authentic output scenarios and explain the types as well as contents of output tasks in the form of micro videos. Students should then be encouraged to watch them before classes through the Chaoxing App.

\subsection{Enabling stage}

The enabling stage includes three tasks:

(1) teachers are required to explain the steps and requirements of sub-production activities;

(2) under the guidance of teachers, students are required to learn and complete the enabling activities, while the teachers would subsequently inspect them;

(3) under the guidance of teachers, students are required to practice output, while teachers would check.

The first task in the enabling stage links to the last task in the motivating stage. The last task in the motivating stage is to explain to the students the types and contents of the output activities. When it comes to the enabling stage, teachers should not only explain how to decompose the output activities into several sub-activities, but also focus on the steps and requirements to complete sub-production activities.

The second task in the enabling stage is to guide students to carry out selective learning according to the requirements of sub-activities, supervise students to complete enabling activities, and check their quality. After mastering the basic forms of language expression, students need to learn the discourse structure. Teachers can use PPT to share excellent works by the students as input materials for learning discourse structures. With the development of students' abilities, teachers should encourage their students to use expression structures with individual characteristics. When guiding students to process input materials, teachers should timely check the content, language form, and discourse structure chosen by the students, so as to understand the effect of the students' choice of learning.

The third task in the enabling stage involves output exercises and reviews. By displaying the exercises on PPT, teachers can then group the students in pairs or in larger groups to carry out those exercises and give immediate feedback upon completion.

\subsection{Assessment stage}

Teacher-student collaborative assessment (TSCA) is an essential part of POA. TSCA is divided into three 
stages: pre-class preparation, in-class implementation, and after-class activities.

\subsubsection{Pre-class preparation}

Before class, upon the submission of students' output results as required, teachers need to complete five main tasks.

(1) Quickly scan and look for typical samples. It is recommended that TSCA use 1 class hour and select 1 medium quality sample that can be modified and evaluated.

(2) Review the typical samples. After selecting the typical samples, review the samples one by one based on the teaching objectives. On the other hand, teachers should select key points for marking in order to overcome the disadvantage where the expected results cannot be met from detailed marking.

(3) Determine the focus and design the teaching procedures of TSCA. At the end of the review, it is necessary to determine the assessment focus and design specific steps for implementing TSCA in class. Due to the limited class time, selective assessment is more effective than comprehensive assessment. Depending on the teaching objectives, different emphases can be placed each time.

(4) Prepare student assessment materials. First of all, copy the original materials from the typical samples (excluding the modifications made by teachers), and then highlight the key points of assessment, so as to avoid the issue of students not recalling during classes. In order to avoid embarrassment, it is recommended that the names of the students remain confidential.

(5) Develop exercises to reinforce and consolidate the key points or difficulties in TSCA. According to the key points and difficulties in the assessment, appropriate exercises should be prepared to help students solve the common problems in TSCA.

\subsubsection{In-class implementation}

First of all, PPT can be used to present the key points of evaluation. According to the assessment focus, students can then make their own comments, learn from the beautiful sentence patterns and advanced phrases written by other students, as well as discover the shortcomings of other students, so as to alert themselves to avoid making similar mistakes in writing. Then, a discussion on the assessment should be carried out in pairs. Finally, teacher assessment can enhance students' attention to typical problems.

\subsubsection{After-class activities}

After the class assessment, students are required to revise their compositions and submit their final compositions to the correcting network application before the following class. By scoring and commenting on the machine, it does not only show the students' results, but also automatically record the results and form portfolios.

Teachers can then select two excellent works for students to learn and appreciate.

\section{Conclusion}

In general, the combination of CALL and POA makes teaching resources richer and timelier. The use of CALL-based POA should be encouraged in future teaching. CALL-based POA breaks the time limit of traditional classroom teaching and enhances the communication as well as interaction between teachers and students. It is necessary to assess and provide feedback on the effect of online learning on students in class. At the same time, it is important to invariably focus on being people-oriented and open a door for students to learn independently. 


\section{Disclosure statement}

The author declares that there is no conflict of interest.

\section{References}

[1] Wen Q, 2020, Output-Oriented Approach: Theoretical Innovation and Exploration of Foreign Language Education in China, Foreign Language Teaching and Research Press, Beijing.

[2] Wen Q, 2018, “Output Oriented Approach" and Teaching Chinese as a Foreign Language. World Chinese Teaching, 2018B(3): 387-400.

[3] Shu D, Zhuang Z, 2008, Modern Foreign Language Teaching: Theory, Practice and Methods, Shanghai Foreign Language Education Press, Shanghai.

[4] Dan L, 2010, A Salutary Lesson from a Computer-based Self-Access Language Learning Project. Computer Assisted Language Learning, 23(4): 343-359.

[5] Liu P-L, Chen C-J, Chang Y-J, 2010, Effects of a Computer-assisted Concept Mapping Learning Strategy on EFL College Students' English Reading Comprehension. Pergamon, 54(2): 436-445.

[6] Chen C-J, 2008, Intelligent Web-based Learning System with Personalized Learning Path Guidance. Pergamon, 51(2): 787-814. 